\title{
Vanishing Ponds and Regional Water Resources in Taoyuan, Taiwan
}

\author{
Yuei-An Liou ${ }^{1,2,3, *}$, Hsiao-Lan Liu ${ }^{2,4}$, Tai-Sheng Wang ${ }^{1,2}$, and Chin-Hung Chou ${ }^{2,4}$ \\ ${ }^{1}$ Center for Space and Remote Sensing Research, National Central University, Zhongli, Taiwan, R.O.C. \\ ${ }^{2}$ Taiwan Group on Earth Observations, Hsinchu, Taiwan, R.O.C. \\ ${ }^{3}$ Taiwan Geographic Information System Center, Taipei, Taiwan, R.O.C. \\ ${ }^{4}$ Department of Hakka Language and Social Science, National Central University, Zhongli, Taiwan, R.O.C.
}

Received 30 December 2013, revised 28 March 2014, accepted 2 December 2014

\begin{abstract}
Taiwan has a Subtropic to Tropical climate, but its precipitation varies widely in response to seasonal effects and weather events such as Typhoon and Meiyu systems. Precipitation must be held back in reservoirs to provide and regulate sufficient water supply. Balancing the irregular precipitation and increasing water demands generates tremendous pressure on water resources management for the water stored in the Shihmen Reservoir, which is the major unitary water supply system in the Greater Taoyuan Area. Such pressure will be significantly enlarged due to the huge 17 billion USD Taoyuan Aerotropolis Project. In earlier days many small artificial ponds (a common terminology in this article), including irrigation ponds, fishery ponds and others, were built to cope with water shortages in Taoyuan County. These small storage ponds provided a solution that resolved seasonal precipitation shortages. Unfortunately, these ponds have been vanishing one after another one due to regional industrialization and urbanization in recent decades and less than $40 \%$ of them still remain today. There is great urgency and importance to investigating the link between vanishing ponds and water resources management. Remote sensing technology was used in this study to monitor the environmental consequences in the Taoyuan area by conducting multi-temporal analysis on the changes in water bodies, i.e., ponds. SPOT satellite images taken in 1993, 2003, and 2010 were utilized to analyze and assess the importance of small-scale ponds as water conservation facilities. It was found that, during the seventeen years from 1993 - 2010, the number of irrigation ponds decreased by $35.94 \%$. These ponds can reduce the burden on the major reservoir and increase the water recycling rate if they are properly conserved. They can also improve rainfall interception and surface detention capabilities, and provide another planning advantage for regional water management.
\end{abstract}

Key words: Ponds, Water resource, Remote sensing technology, Water body changes

Citation: Liou, Y. A., H. L. Liu, T. S. Wang, and C. H. Chou, 2015: Vanishing ponds and regional water resources in Taoyuan, Taiwan. Terr. Atmos. Ocean. Sci., 26, 161-168, doi: 10.3319/TAO.2014.12.02.01(EOSI)

\section{INTRODUCTION}

Taiwan is located in a rainy region with precipitation higher than the world average. However, it is also considered a country with great demand for water resources. This is due to the fact that only a small portion of the water brought by precipitation can be stored over land as most of the water flows directly into the sea through various rivers in response to steep mountain terrain. The water demand is critically affected when the reservoir suffers with sedimentation.

In earlier times, people excavated ponds on the Taoyuan tableland to resolve the water shortage problem for agricultural irrigation. These excavated ponds included irrigation

\footnotetext{
* Corresponding author

E-mail:yueian@csrsr.ncu.edu.tw
}

ponds, fish ponds and others, used as adjustable irrigation facilities for agriculture development over the impermeable red and yellow soil. It was estimated that the number of ponds reached nearly 8000 in the past (Chen 2003). These ponds were gradually replaced by a variety of land uses and thus their number decreased with the establishment of Taoyuan Canal, Shihmen Reservoir, and Shihmen Canal. It was found that there were only 3345 ponds left in 2008 (Chyi and Wu 2009). Needless to say, the fast expansion of urbanization and industrialization over the past two decades with major national construction projects such as Taoyuan International Airport are major causes in the decrease in the number of ponds in Taoyuan County (Liou et al. 2013).

Currently the Taoyuan Aerotropolis and Taoyuan 
International Airport MRT are being realized. The issue of conserving ponds with a variety of functions draws great attention from the people and government. This is especially important because ponds represent one of the major factors in the development of basic Hakka culture. Ponds are required for the preservation, promotion and sustainable development of Hakka culture (Liou and Gong 2012). The entire world is concentrated on conservation, development and water resource recycling. The "Recycle a Bucket of Water a Day" concept was proposed on World Water Day, 22 March 2013, with the goal of popularizing water saving and increasing the water recycling rate. Therefore, ponds are usually excavated as water storage to reduce the societal dependence on reservoirs and as detention ponds to mitigate the disasters caused by excessive runoff in flood prevention. For example, Lo (2012) selected eight locations for temporary retention pond construction to enhance the flood mitigation effect. Stored flood water may then be drained out through pumping or connecting drainage ditches. Ponds are one of the important water conservancy facilities for conserving water resources and preventing disasters. However, ponds have multiple functions (aquaculture, water storage, flood prevention, and irrigation) on the Taoyuan tableland that changed with the development of society and economy. The importance of ponds has been gradually lost due to the development of modern water conservation.

Lin et al. (2000) collected historical indexes of the area, circumference and shape of ponds in Luchu Township to analyze the landscape changes in ponds in the temporal and spatial changes using patch shape indices and nonparametric statistical methods. They found that the anthropogenic influences on the vanishing ponds were very obvious during the period from 1966 - 1993. Chang (2001) classified the Taoyuan tableland into four categories including water area, farmland, buildings and others to assessed the impact of terrestrial wetland changes in the environment using Markov Chain Model and Cluster Analysis. The results showed that the number of vanishing ponds was significant. The water areas were reduced from 12 - 9\% in total area during the period from 1982 - 1995. In contrast, Fang and Chao (2008) indicated that the number of ponds in the Taoyuan tableland was reduced from 4521 - 1545 during the period from 1926 - 1999. In terms of area, they were decreased from $11.8-3.8 \%$. Although there are discrepancies in the number and areas of ponds among different studies, the decreasing trend is consistent.

The changes in LULC (Land Use \& Land Cover) greatly influenced water resources. Previous studies have shown that the change in LULC may affect rainfall patterns and surface temperature (Liou et al. 1998; Lin et al. 2008a, b, 2011), evapotranspiration (ET) signatures (Kalma et al. 2008; Li et al. 2009; Chang et al. 2010; Wang 2010; Wang and Dickinson 2012; Liou and Kar 2014), and soil moisture state (Liou et al. 2001; Liu et al. 2002). These changes may consequently impact the agricultural water resources and ir- rigation area, farming activities, and irrigation area and dry land (Judge et al. 1999; Kabat et al. 2004; Feddema et al. 2005; Juang et al. 2007; Kueppers et al. 2007). Understanding the LULC influences using integrated scientific methods such as measurement in situ, remote sensing and model establishing and their significance on the conservation and use of water resources is crucial.

Although the researches have consistently shown the overall trends in vanishing pond area and the decreasing number of ponds, the relationship between these factors and water resources in the local area have not been analyzed and investigated to our knowledge. For example, how much pond area has disappeared during the period from 1993 - 2010? How much water storage has been lost associated with the loss of vanished ponds? How large an agricultural field may be supplied by the existing ponds? In other words, what roles do ponds play for the interception, storage, utilization and allocation of the hydrological cycle? This study utilized multi-temporal satellite images to interpret the LULC categories in the Taoyuan area and examined the changes in LULC. Water body changes in ponds were analyzed in this area to improve our understanding of the relationship between the vanishing pond area and available quantity of water. Results from this study are expected to increase the regional water resources and stabilize economy and industry development.

\section{RESEARCH METHODS}

\subsection{Image Processing}

Remote sensing technology was developed in the 1960s and has gradually become a practical and comprehensive method of observation along with the development of modern physics, space technology, electronic technology, computing technology, information science, and environmental science (Chang et al. 2010; Liou et al. 2010). However, the satellite images contain inaccuracies associated with radiation measurements (caused by atmospheric scattering and sunlight incident angle) and geometry (caused by distortion or deformation due to vehicle form, orbital parameter of aviation or surface curvature). Thus, the data collected by sensors may not properly correspond to clutter reflections. The ground sample position may also not correctly match the image location coordinates on the map. This is the socalled "image distortion" problem (Chang et al. 2012; Liou et al. 2012). The captured images are therefore corrected before application for classification. This is called "image correction" or "image processing" including geometric correction and radiometric correction (Wang 2010).

\subsection{Image Classification}

The ground spectrum reflection information is recorded using the digital numbers $(\mathrm{DN})$ in the images. It gives a 
specific DN value in an image through certain statistical methods for further calculation and analysis. The specific value stands for one corresponding type of LULC. There are two typical image classification methods based on the spectral pattern recognition method, namely Unsupervised Classification and Supervised Classification. The spectral pattern represents a cluster of remote sensing information in a feature space.

This study carried out image classification using nonsupervised classification owing to the lack of the in situ LULC samples. In addition to saving time for selecting the training samples of concern in the supervised classification, the non-supervised classification can be used to implement statistical methods for the purpose of classification. This simplifies the image process but also targets the numbers of interest. It does not misidentify the ground practical categories at the same time.

\subsection{Classification Accuracy}

It is necessary to assess the accuracy of the images after classification. The method that is often adopted at most is error matrix, including the overall accuracy, producer's accuracy, user's accuracy, and Kappa index, to assess the accuracy of images. Therefore, error matrix will be taken to be the standard of accuracy assessment of image classification. The definitions are given in Eqs. (1) - (4):

$$
\text { Overall Accuracy }=\frac{\sum_{i=1}^{n} X_{i i}}{\sum_{i=1}^{n} \sum_{j=1}^{n} X_{i j}} \times 100 \%
$$

Producer's Accuracy $=\frac{X_{n n}}{\sum_{j=1}^{n} X_{n j}} \times 100 \%$

User's Accuracy $=\frac{X_{n n}}{\sum_{i=1}^{n} X_{i n}} \times 100 \%$
Kappa $=\frac{P_{0}-P_{1}}{1-P_{1}}$

where $X$ is the category of LULC, $P_{0}=\sum_{i=1}^{n} X_{i i} / N$ represents the overall accuracy, $N$ is the overall sample of DN, and $P_{1}=\sum_{i=1}^{n}\left(X_{i} \times X_{\bullet_{i}}\right) / N^{2}$ is the expected accuracy.

\section{STUDY AREA}

Taoyuan County is located in Northwest Taiwan and divided into thirteen townships as shown in Fig. 1, with the county contains many tablelands. The infertile soil of Taoyuan County is difficult to farm because the terrain lacks large rivers for irrigation and is covered with sand brought in by the sea breeze. The Dahan and Nankan Rivers form the water system in this area. The other available rivers and streams are short with little visible water in the images used in our study. Water shortage is a historical problem for agricultural activities in Taoyuan County. Ponds were historically excavated for farming irrigation facilities in Taoyuan tableland to resolve water shortages. These ponds were gradually replaced by irrigation facilities established later on, including the Taoyuan Canal built in the 1920s, and Shimen Reservoir and Shimen Canal constructed in the 1960s. When the fallow compensation policy was implemented, it caused ponds to vanish even faster. The ponds were excavated for agricultural irrigation demand, but vanished because of the advanced facilities introduced for farm irrigation as well as industrialization. For the time-being the Taoyuan tableland once again faces the problem of water demand linked to industrialization and urbanization expansion. Better management of water resources has become more important than ever.

Remote sensing technology can be used to continuously observe large-scale LULC patterns over an extensive period of time. The collected data can be the foundation for LULC identification and change monitoring. This study

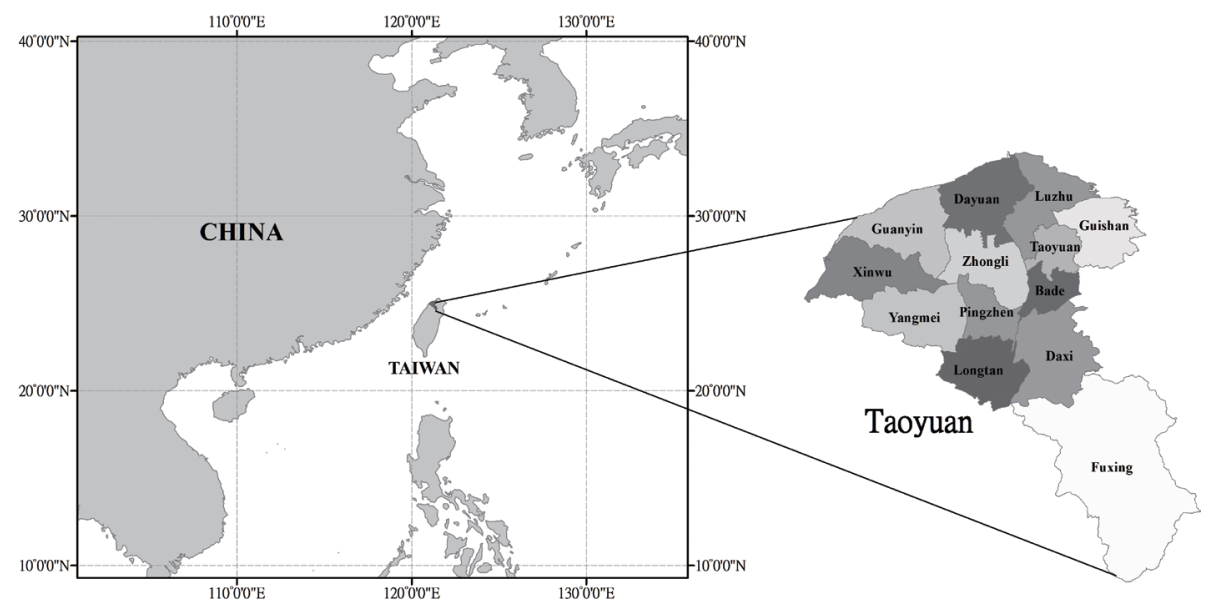

Fig. 1. The geographical location of Taoyuan County. 
utilized three multi-temporal serial satellite SPOT images taken on 12/30/1993 (SPOT 2), 07/07/2003 (SPOT 5), and $12 / 27 / 2010$ (SPOT 5), whose spatial resolutions are 12.5, 10, and $10 \mathrm{~m}$, respectively. These images are applicable to observing the evolving LULC trend in Taoyuan, including the ponds (water body) between 1993 - 2010. Both images were acquired in the same month (December) so that the seasonal effect on the LULC classification is minimized. These images were taken during the harvest so that rice fields would not be misinterpreted as water bodies. Note that the rivers in Taoyuan are relatively small and thus nearly invisible in the image pixels. The ponds are located mostly in the plains area rather than in mountain or forest areas. This study used image processing techniques to cut out Fuxing Township, the area southeast to the hill and river boundaries of Taoyuan County. This was done to exclude the influence of water bodies such as rivers and reservoirs on our investigation. There are essentially no irrigation ponds in Fuxing Township where the LULC is most likely forests and partially visible rivers in the image pixels. Under such circumstances, it is reasonable to state that the classified water body well represents the overall water body type. Only twelve out of thirteen townships are considered in our study, as shown in Fig. 2. There fewer forests in the plains area. This fact assures minimized misinterpretation of non-farming vegetation as farmland.

\section{RESULTS AND DISCUSSION}

This research applied the iterative self-organizing nonsupervised classification data analysis technique (ISODATA) to reduce the complex landscape influence on accuracy in the study area. Compared with supervised classification this method saves time. However, its unstable classification accuracy will change with less accurate complicated land- scapes. Therefore, to reduce the landscape complications, this study classified LULC into three categories including water body (ponds), vegetation (farmland), and non-vegetation (building and barren land) as shown in Fig. 3. Two hundred sixty-seven random check points were therefore utilized for accuracy assessment, as shown Fig. 4. The error matrix is shown in Tables 1, 2, and 3 .

From Tables 1,2, and 3, we can find that after ISODATA classification the overall accuracy and the Kappa index values were over $90 \%$ and 0.8 , respectively. This shows that the classification reliability in the three images is very high. However, the spatial resolution scale may affect the classification accuracy. For example, producer and user accuracy misjudgments are generated in the non-vegetation area in 1993 and the water body areas of 2003 and 2010 because some random check points are located on the boundary of the two categories. Therefore, it is difficult to quantify the accuracy of categories. In general, the accuracy is able to stand for the category characteristics in the study area.

Table 4 shows that the LULC patterns changed significantly during the period from 1993 - 2010. The number of water bodies (ponds) decreased by $35.94 \%$ (10.55 million $\mathrm{m}^{2}$ ). The building and barren land growth was from ponds and farmland by 6.2 and $93.8 \%$, respectively. The vanishing water bodies indicate that water storage was significantly reduced, which can be approximately quantified by neglecting the surface infiltration and runoff effects through statistical analysis of images taken in 1993, 2003, and 2010. Based on the average pond depth of roughly 2 - 3 m (Taiwan Institute of Urban Planning 2008), the water body storage capacity in the study area was reduced by $21.10-31.65$ million $\mathrm{m}^{3}$ (million tons) in seventeen years. Comparing the water quantity of vanishing ponds with the water consumption for irrigation supplied by Shihmen Reservoir in 2010, we adopted

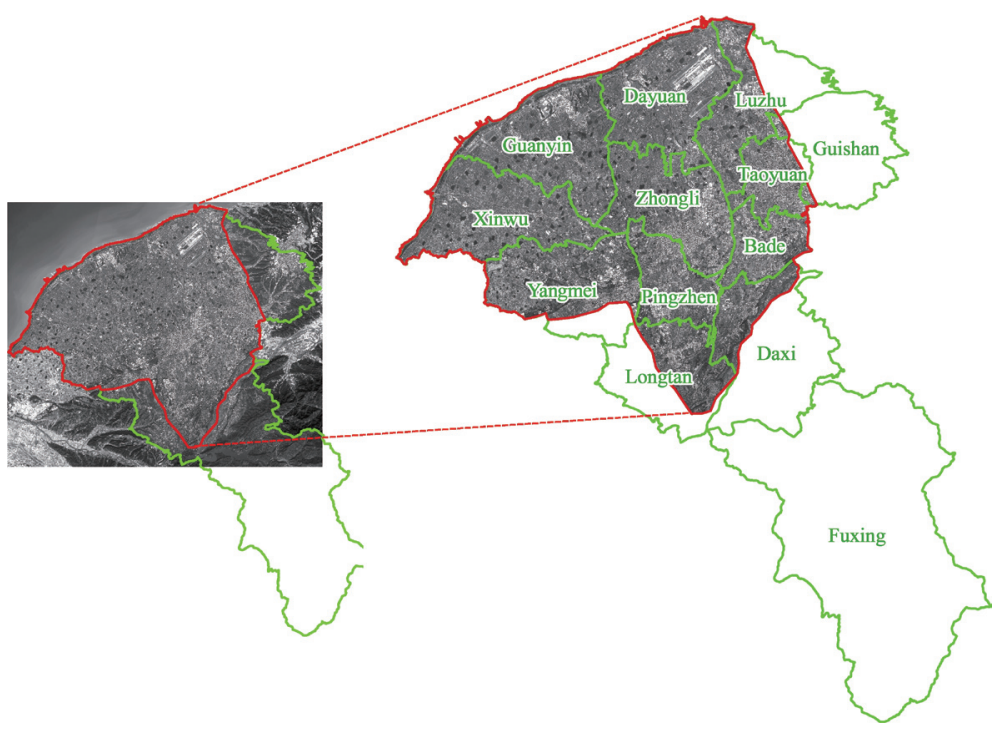

Fig. 2. The study area. 
(a)

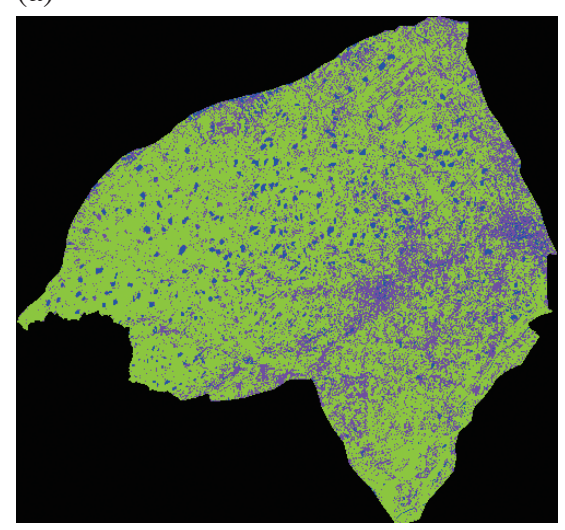

(b)

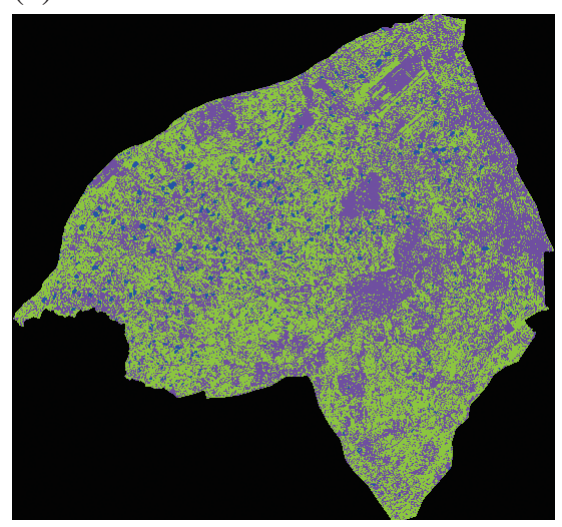

(c)

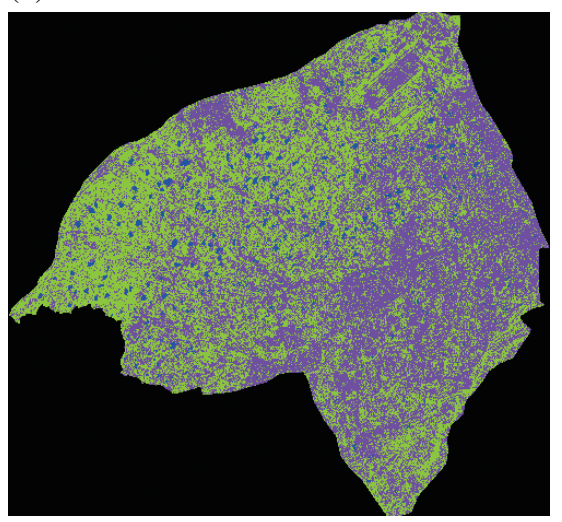

Fig. 3. The classification map (a) 30 December 1993, (b) 07 July 2003, and (c) 27 December 2010 (blue: water body, green: vegetation, purple: non-vegetation) (adopted from Liou et al. 2013).

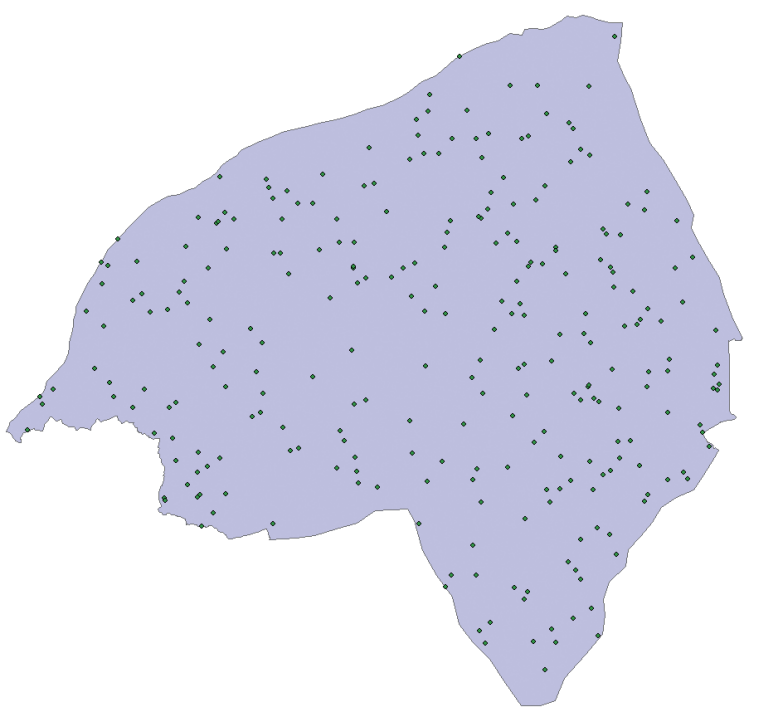

Fig. 4. Distribution of the 267 random check points.

Table 1. Error matrix of ISODATA (iterative self-organizing non-supervised classification data analysis technique) classification in 1993.

\begin{tabular}{|c|c|c|c|c|c|c|}
\hline & \multirow{2}{*}{1993} & \multicolumn{5}{|c|}{ Classification } \\
\hline & & Water & Vegetation & Non-Vegetation & Total & Producer's Accuracy \\
\hline \multirow{6}{*}{ 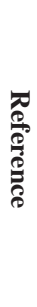 } & Water & 10 & 0 & 0 & 10 & $100 \%$ \\
\hline & Vegetation & 0 & 196 & 2 & 198 & $98.99 \%$ \\
\hline & Non-Vegetation & 0 & 16 & 43 & 59 & $72.88 \%$ \\
\hline & Total & 10 & 212 & 45 & 267 & \\
\hline & User's accuracy & $100 \%$ & $92.45 \%$ & $95.56 \%$ & & \\
\hline & Overall Accuracy & $93.26 \%$ & kappa & 0.84 & & \\
\hline
\end{tabular}


Table 2. Error matrix of ISODATA classification in 2003.

\begin{tabular}{|c|c|c|c|c|c|c|}
\hline & \multirow{2}{*}{2003} & \multicolumn{5}{|c|}{ Classification } \\
\hline & & Water & Vegetation & Non-Vegetation & Total & Producer's Accuracy \\
\hline \multirow{6}{*}{ 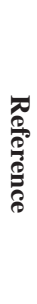 } & Water & 8 & 0 & 0 & 8 & $100 \%$ \\
\hline & Vegetation & 0 & 121 & 6 & 127 & $95.28 \%$ \\
\hline & Non-Vegetation & 1 & 12 & 119 & 132 & $90.15 \%$ \\
\hline & Total & 9 & 133 & 125 & 267 & \\
\hline & User's accuracy & $88.89 \%$ & $90.98 \%$ & $95.2 \%$ & & \\
\hline & Overall Accuracy & $92.88 \%$ & kappa & 0.88 & & \\
\hline
\end{tabular}

Table 3. Error matrix of ISODATA classification in 2010.

\begin{tabular}{|c|c|c|c|c|c|c|}
\hline & \multirow{2}{*}{2010} & \multicolumn{5}{|c|}{ Classification } \\
\hline & & Water & Vegetation & Non-Vegetation & Total & Producer's Accuracy \\
\hline \multirow{6}{*}{ 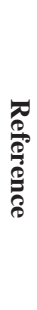 } & Water & 8 & 2 & 0 & 10 & $80 \%$ \\
\hline & Vegetation & 0 & 109 & 6 & 115 & $94.78 \%$ \\
\hline & Non-Vegetation & 1 & 6 & 135 & 142 & $95.07 \%$ \\
\hline & Total & 9 & 117 & 141 & 267 & \\
\hline & User's accuracy & $88.89 \%$ & $93.16 \%$ & $95.74 \%$ & & \\
\hline & Overall Accuracy & $94.38 \%$ & kappa & 0.90 & & \\
\hline
\end{tabular}

Table 4. The LULC changes in 1993, 2003, and 2010.

\begin{tabular}{cccc}
\hline Land Type & $\mathbf{1 9 9 3}\left(\mathbf{m}^{2}\right)$ & $\mathbf{2 0 0 3}\left(\mathbf{m}^{2}\right)$ & $\mathbf{2 0 1 0}\left(\mathbf{m}^{2}\right)$ \\
\hline Water & 29352656 & 18945800 & 18804200 \\
Vegetation & 444161250 & 310832500 & 281818300 \\
Non-Vegetation & 156671563 & 300244100 & 329399900 \\
\hline Total & 630185469 & 630022400 & 630022400 \\
\hline
\end{tabular}

statistical data from the authority (Statistics of Water Control for the Water Storage Facilities, Northern Region Water Resources Office 2013: http://www.wranb.gov.tw/ct.asp?xI tem $=2564 \& \mathrm{ctNode}=325 \& \mathrm{mp}=5$ ). According to the statistical data from 2010, the total irrigation water supply from the Shimen Reservoir in Taoyuan County for the year is approximately 153.69 million tons. Since the water storage capacity of the vanished ponds is around $21.10-31.65$ million tons, it accounts for roughly $13.73-20.59 \%$ of the irrigation water required in the same year, as shown in Table 5.

According to the statistical data from 2007, the total cultivated area of Taoyuan County is approximately 37.55 thousand hectares (ha), which is equivalent to $30.75 \%$ of the total area in Taoyuan County (Taiwan Institute of Urban Planning 2008). Based on the database from the authority (Taoyuan Irrigation Association 2013: http://doie.coa.gov. tw/about/about.asp?uc=tia), it is estimated that 0.02 million tons of water is needed for irrigating one ha of farmland each planting season. Thus, the water stored in the vanished ponds was sufficient to irrigate about $1.06-1.58$ thousand ha of the farmland, which accounts for $2.82-4.21 \%$ of the total cultivated area.

The potential importance of fallow activation in Taoyuan County is further examined. According to the statistical data of 2011 the existing fallow area in Taoyuan County was approximately 26.86 thousands ha (Taiwan Institute of Urban Planning 2008). If we comply with the activation strategy promoted by the government, about $3.95-5.88 \%$ of fallow area can be activated with the water stored in the vanished ponds to reduce the water supply pressure on the Shihmen Reservoir. Shihmen Reservoir is currently the major water supply for farming and public use in Taoyuan. If we 
Table 5. Water storage capacity of vanished ponds compared to water supply of Shihmen Reservoir in 2010

\begin{tabular}{ccc}
\hline Water Storage Capacity of Vanished Ponds & Water Supply of Shihmen Reservoir & Ratio \\
\hline \multirow{2}{*}{$21.10-31.65$ million tons } & 153.69 million tons for irrigation & $13.73-20.59 \%$ \\
& 750.84 million tons for public use & $2.81-4.22 \%$ \\
\hline
\end{tabular}

can efficiently activate additional water ponds, the regional water resources will be increased and thus lessen the water supply burden on the Shimen Reservoir.

\section{CONCLUSIONS}

Multi-temporal SPOT satellite images (1993, 2003, and 2010) were utilized to identify the changes in LULC in Taoyuan. The results showed the water body storage area (ponds) was reduced by $35.94 \%$, roughly equal to 10.55 million $\mathrm{m}^{2}$, within eighteen years (1993 - 2010). The amount of water supply lost is around $21.10-31.65$ million tons by assuming an average pond depth ranging from $2-3 \mathrm{~m}$. If 0.02 million tons of water are needed for the irrigation of one ha of farmland each planting, the decreased water supply due to vanishing ponds in the 17-year period of concern could be used to irrigate $1.06-1.58$ thousand ha of farmland, corresponding to a reduction of $2.82-4.21 \%$ for the total cultivated area in Taoyuan County.

The irrigation efficiency from vanishing pond area and the changes in water resources were analyzed. The results demonstrate that the ponds in Taoyuan area have multiple functions that moderate the demand for public water supply and agricultural irrigation in the area. It has been reported that water storage ponds can recharge groundwater and prevent land subsidence. Accordingly, we must maintain and conserve important public assets. It is necessary to emphasize the water recycling rate from ponds to stabilize regional development. We shall properly recognize the function and value of the existing ponds, which account for $64.06 \%$ (100 - 35.94\%) of the number of ponds at most. The water storage ponds on Taoyuan tableland improve the capabilities of regional rainfall interception and surface detention and provide another planning advantage for regional water management.

Note that it is our ultimate goal to offer policy makers suggestions based on scientific study results for improving water resources management. We will thus continue to investigate the impacts of LULC evolution on the climate, hydrology cycle and society in the future.

Acknowledgements The authors are extremely grateful to the CSRSR satellite receiving station for providing the images data of SPOT-2 and SPOT-5. This research is supported by the grants from National Science Council (NSC) of Taiwan, NSC 102-2111-M-008-027 and NSC 102-2221E-008-034.

\section{REFERENCES}

Chang, T. K., 2001: Study of the wetland land changes to impact the environment in Taoyuan tableland, Report of National Science Council Research Project. (in Chinese)

Chang,T.Y.,Y.A.Liou,C.Y.Lin, S.C.Liu, and Y.C.Wang, 2010: Evaluation of surface heat fluxes in Chiayi plain of Taiwan by remotely sensed data. Int. J.Remote Sens., 31, 3885-3898, doi: 10.1080/01431161.2010.483481. [Link]

Chang, T. Y., Y. C. Wang, C. C. Feng, A. D. Ziegler, T. W. Giambelluca, and Y. A. Liou, 2012: Estimation of root zone soil moisture using apparent thermal inertia with MODIS imagery over a Tropical Catchment in Northern Thailand. IEEE Trans. Geosci. Remote Sensing, 5, 752-761, doi: 10.1109/JSTARS.2012.2190588. [Link]

Chen, H. T., 2003: From Ponds to Irrigations: The Evolution of the water resources in Tao-yuan Plateau. Dong Hwa Journal of Humanities, 5, 183-208. (in Chinese)

Chyi, S. J. and H. J. Wu, 2009: Taoyuan Tableland Encyclopedia of Taiwan. (in Chinese)

Fang, W. T. and S. D. Chao, 2008: A digital modeling for best management practice at pondscape scales in Taoyuan. The $6^{\text {th }}$ Taipei International Digital Earth Symposium, 312-322. (in Chinese)

Feddema, J. J., K. W. Oleson, G. B. Bonan, L. O. Mearns, L. E. Buja, G. A. Meehl, and W. M. Washington, 2005: The importance of land-cover change in simulating future climates. Science, 310, 1674-1678, doi: 10.1126/ science.1118160. [Link]

Juang, J. Y., A. Porporato, P. C. Stoy, M. S. Siqueira, A. C. Oishi, M. Detto, H. S. Kim, and G. G. Katul, 2007: Hydrologic and atmospheric controls on initiation of convective precipitation events. Water Resour. Res., 43, W03421, doi: 10.1029/2006WR004954. [Link]

Judge, J., A. W. England, W. L. Crosson, C. A. Laymon, B. K. Hornbuckle, D. L. Boprie, E. J. Kim, and Y. A. Liou, 1999: A growing season land surface process/radiobrightness model for wheat-stubble in the Southern Great Plains. IEEE Trans. Geosci. Remote Sensing, 37, 2152-2158, doi: 10.1109/36.789611. [Link]

Kabat, P., M. Claussen, S. Whitlock, J. H. C. Gash, L. B. de Guenni, M. Meybeck, R. Pielke, C. J. Vörösmarty, R. W. A. Hutjes, and S. Lütkemeier, 2004: Vegetation, Water, Humans and the Climate: A New Perspective 
on an Interactive System, Global Change - The IGBP Series, Springer-Verlag Berlin Heidelberg, Berlin, 566 pp, doi: 10.1007/978-3-642-18948-7. [Link]

Kalma, J. D., T. R. McVicar, and M. F. McCabe, 2008: Estimating land surface evaporation: A review of methods using remotely sensed surface temperature data. Surv. Geophys., 29, 421-469, doi: 10.1007/s10712008-9037-z. [Link]

Kueppers, L. M., M. A. Snyder, and L. C. Sloan, 2007: Irrigation cooling effect: Regional climate forcing by land-use change. Geophys. Res. Lett., 34, L03703, doi: 10.1029/2006GL028679. [Link]

Li, Z. L., R. Tang, Z. Wan, Y. Bi, C. Zhou, B. Tang, G. Yan, and X. Zhang, 2009: A review of current methodologies for regional evapotranspiration estimation from remotely sensed data. Sensors, 9, 3801-3853, doi: 10.3390/s90503801. [Link]

Lin, C. Y., F. Chen, J. C. Huang, W. C. Chen, Y. A. Liou, W. N. Chen, and S. C. Liu, 2008a: Urban heat island effect and its impact on boundary layer development and landsea circulation over northern Taiwan. Atmos. Environ., 42, 5635-5649, doi: 10.1016/j.atmosenv.2008.03.015. [Link]

Lin, C. Y., W. C. Chen, S. C. Liu, Y. A. Liou, G. R. Liu, and T. H. Lin, 2008b: Numerical study of the impact of urbanization on the precipitation over Taiwan. Atmos. Environ., 42, 2934-2947, doi: 10.1016/j. atmosenv.2007.12.054. [Link]

Lin, C. Y., H. M. Hsu, Y. F. Sheng, C. H. Kuo, and Y. A. Liou, 2011: Mesoscale processes for super heavy rainfall of Typhoon Morakot (2009) over Southern Taiwan. Atmos. Chem. Phys., 11, 345-361, doi: 10.5194/ acp-11-345-2011. [Link]

Lin, Y. P., T. P. Teng, and J. C. Cheng, 2000: Patch shape indices and statistical method in the study of landscape change of irrigation pond. Department of Geography, C.C.U. Reports of Geographical Studies, No. 13, 95125. (in Chinese)

Liou, Y. A. and Y. C. Gong, 2012: Taoyuan water conservancy ppace and Hakka environmental changes - landscape. Hakka Academic Research Projects, Council for Hakka Affairs. (in Chinese)

Liou, Y. A. and S. K. Kar, 2014: Evapotranspiration estimation with remote sensing and various surface energy balance algorithms-A review. Energies, 7, 2821-2849, doi: 10.3390/en7052821. [Link]

Liou, Y. A., E. J. Kim, and A. W. England, 1998: Radiobrightness of prairie soil and grassland during dry-down simulations. Radio Sci., 33, 259-265, doi: 10.1029/97RS03655. [Link]

Liou, Y. A., S. F. Liu, and W. J. Wang, 2001: Retrieving soil moisture from simulated brightness temperatures by a neural network. IEEE Trans. Geosci. Remote Sensing, 39, 1662-1672, doi: 10.1109/36.942544. [Link]

Liou, Y. A., S. K. Kar, and L. Chang, 2010: Use of high-resolution FORMOSAT-2 satellite images for post-earthquake disaster assessment: A study following the 12 May 2008 Wenchuan Earthquake. Int. J. Remote Sens., 31, 3355-3368, doi: 10.1080/01431161003727655. [Link]

Liou, Y. A., H. C. Sha, T. M. Chen, T. S. Wang, Y. T. Li, Y. C. Lai, M. H. Chiang, and L. T. Lu, 2012: Assessment of disaster losses in rice paddy field and yield after tsunami induced by the 2011 Great East Japan earthquake. J. Mar. Sci. Technol., 20, 618-623, doi: 10.6119/JMST-012-0328-2. [Link]

Liou, Y. A., T. S. Wang, and H. P. Chan, 2013: Impacts of pond change on the regional sustainability of water resources in Taoyuan, Taiwan. Adv. Meteorol., 2013, 1-6, doi: 10.1155/2013/243456. [Link]

Liu, S. F., Y. A. Liou, W. J. Wang, J. P. Wigneron, and J. B. Lee, 2002: Retrieval of crop biomass and soil moisture from measured 1.4 and $10.65 \mathrm{GHz}$ brightness temperatures. IEEE Trans. Geosci. Remote Sensing, 40, 12601268, doi: 10.1109/TGRS.2002.800277. [Link]

Lo, A., 2012: Rainwater utilization to reduce flooding in low-lying areas of Taipei City, Taiwan. J. Mar. Sci. Technol., 20, 657-661.

Taiwan Institute of Urban Planning, 2008: Taoyuan County Agricultural Resources Spatial Planning Program, 127 pp. (in Chinese)

Wang, K. and R. E. Dickinson, 2012: A review of global terrestrial evapotranspiration: Observation, modeling, climatology, and climatic variability. Rev. Geophys., 50, 1-54, doi: 10.1029/2011RG000373. [Link]

Wang, T. S., 2010: Application of various-scale satellite images to inland water quality monitoring in Taiwan. Ph.D. Thesis, Department of Civil Engineering and Engineering Informatics, Chung Hua University, 292 pp. (in Chinese) 